\title{
CULTURA ORGANIZACIONAL EM INSTITUIÇÕES MILITARES DE ENSINO
}

\author{
J. A. Costa '; N. Araújo ${ }^{2}$; M. F. Danjour ${ }^{3}$ e P. W. S. Oliveira ${ }^{4}$ \\ ${ }^{1,2}$ Academia de Polícia Militar do Rio Grande do Norte \\ ${ }^{3}$ Instituto Federal do Rio Grande do Norte (IFRN) \\ ${ }^{4}$ Universidade Federal de Campina Grande (UFRN) \\ miler.danjour@ifrn.edu.br ${ }^{3}$; patriciawhebber@gmail.com ${ }^{4}$
}

Artigo submetido em agosto/2012 e aceito em fevereiro/2013

\section{RESUMO}

O presente estudo apresenta como objetivo, descrever os elementos que compõem a cultura organizacional presente no Centro de Formação e Aperfeiçoamento da Polícia Militar do Estado do Rio Grande do Norte - Brasil (CFAPM) a partir do modelo dos estilos de funcionamento organizacional de Paz e Mendes. Para tanto, se utilizou de uma pesquisa do tipo descritiva, classificada como sendo um estudo de caso e de natureza predominantemente quantitativa, realizado com 59 policiais militares que trabalham no CFAPM, possibilitando a identificação da cultura organizacional e as relações existentes entre as variáveis sócio demográficas dos indivíduos estudados. Os dados foram tratados por meio de técnicas de estatística, Teste Quiquadrado, o Teste Exato de Fisher e a Analise de
Correspondência. Os resultados obtidos indicaram a predominância do estilo cultural afiliativo a partir da percepção dos policiais pesquisados e apontaram uma significativa relação entre as variáveis sócio demográficas e os estilos culturais, de forma a identificar que tal predominância foi apontada por $55,9 \%$ dos policiais, e que esta se deu em todas as características gerais, percebendo-se que a cultura organizacional absorve influência de acordo com a variação de tais características. Por fim, conclui-se que o presente estudo identifica que o estilo cultural predominante no CFAPM é o afiliativo, o qual possui características de um padrão coletivista, tendo como subcultura o estilo empreendedor.

PALAVRAS-CHAVE: cultura organizacional, polícia militar, centro de formação e aperfeiçoamento.

\section{ORGANIZATIONAL CULTURE IN MILITARY EDUCATION INSTITUTIONS}

\section{ABSTRACT}

This study seeks to identify the organizational culture at the Centre for Development and Improvement of the Military Police of Rio Grande do Norte - Brazil (CFAPM) based on the model of organizational functioning styles of Paz and Mendes. Therefore, this study is considered to be descriptive and is classified as a case study and is predominantly quantitative in nature. It was conducted on 59 police officers working in CFAPM. The study allowed for the identification of the relationship between organizational culture and the sociodemographic subjects studied. The data was processed using statistical techniques applying the Chi-square,
Fisher exact Test and Correspondence Analysis. The results indicated the predominance of the affiliative cultural style and from the police investigated a significant relationship between socio-demographic and cultural styles was seen and identified. Its predominance was evident in $55.9 \%$ of the police. This predominance was seen in all the general characteristics, showing organizational culture is influenced by these general characteristics.. Finally, it is concluded that this study identifies that the cultural style that is predominant in CFAPM, is the affiliative, which has characteristics of standard collectivism, with a developed subculture style.

KEY-WORDS: organizational cultures, military police, centre for development and improvement. 


\section{CULTURA ORGANIZACIONAL EM INSTITUIÇÕES MILITARES DE ENSINO}

\section{INTRODUÇÃO}

Ao se estudar o perfil cultural das organizações públicas no Brasil identificam-se a burocracia, o autoritarismo centralizado, o paternalismo, a ingerência política e a descontinuidade (MOTTA 2006). Essas características interferem diretamente no modo como os colaboradores atuam nessas organizações, observando-se o apego às regras e rotinas, a supervalorização da hierarquia, o paternalismo nas relações e o apego ao poder.

Assim, Guimarães (2000) afirma que no setor público, o desafio colocado para a nova gestão pública é transformar estruturas burocráticas, hierarquizadas que tendem a um processo de isolamento em organizações flexíveis e empreendedoras, alertando para que os serviços oferecidos pelas organizações públicas não se perpetue como sendo de baixa qualidade, gerando uma expectativa aquém do que pode ser oferecido, tanto para os usuários quanto para os prestadores do serviço, gerando dessa maneira um ciclo vicioso de insatisfação e frustração dos gestores e usuários dos serviços.

Todavia, para atender essas novas demandas da sociedade no papel de cliente, os gestores das organizações públicas necessitam compreender qual o modelo cultural que existem em suas organizações, identificando os estilos de funcionamento organizacional, devendo investir na formação dos valores e crenças organizacionais, melhores políticas de recursos humanos e no aumento da eficácia dos seus resultados, perpassando por suas instituições de formação e unidades de ensino. Nesse contexto, insere-se o Centro de Formação e Aperfeiçoamento da Polícia Militar do Rio Grande do Norte (CFAPM).

O CFAPM é um Centro de Formação destinado as Praças da Polícia Militar. Além da formação, há também atividades relacionadas ao aperfeiçoamento, habilitação e a qualificação de policiais militares na graduação de Soldados, Cabos, 3ㄴ, 2ำ e 1은 Sargentos e Subtenentes.

Ao se observar os desafios colocados por Guimarães (2000) para as organizações publicas brasileiras, o presente estudo apresenta como questão central da pesquisa descrever: Quais são os elementos que compõem a cultura organizacional do Centro de Formação e Aperfeiçoamento da Polícia Militar do Rio Grande do Norte a partir do modelo dos estilos de funcionamento organizacional de Paz e Mendes (2008)?

Como objetivo este estudo busca: descrever os elementos que compõem a cultura organizacional presente no Centro de Formação e Aperfeiçoamento da Polícia Militar do Rio Grande do Norte a partir do modelo dos Estilos de Funcionamento Organizacional de Paz e Mendes.

Por fim, além desta parte introdutória o presente estudo discutira os conceitos de cultura e cultura organizacional, a cultura organizacional dentro da perspectiva de Paz e Mendes (2008), em seguida serão feitas as considerações metodológicas, na quinta parte serão apresentados e discutido os resultados, na sexta parte serão feitas as considerações conclusivas e a última parte traz as referências utilizadas neste trabalho. 


\section{CULTURA E CULTURA ORGANIZACIONAL}

De modo geral, a literatura que trata acerca da cultura e cultura organizacional são compostas por percepções conceituais distintas acerca do tema, na qual Freitas (2007) afirma que, assim como os estudos organizacionais, a cultura nas organizações se beneficia de um conhecimento plural e interdisciplinar, que parece sempre padecer de certa ambiguidade em relação aos seus constructos e definições de termos específicos. Desta forma este capítulo pretende discutir as diferentes visões conceituais, além de mostrar predominantemente dentro de uma perspectiva funcionalista o processo de formação, mudança, níveis de análise e compreensão da cultura organizacional.

Chauí (1999) apresenta dois significados básicos iniciais da noção de Cultura. O primeiro indica sua origem etimológica vinda do verbo latino colere, que significa cultivar, criar, tomar conta e cuidar, Cultura significa o cuidado do homem com a Natureza. Morgan (1996) corrobora dizendo que a palavra cultura é uma metáfora emprestada da experiência de cultivo da terra. Assim, a cultura era o cultivo ou a educação do espírito das crianças para se tornarem membros excelentes ou virtuosos da sociedade pelo aperfeiçoamento e refinamento das qualidades naturais (caráter, índole, temperamento).

O segundo significado remonta ao século XVIII quando Cultura passou a indicar o resultado da formação das pessoas expressos "em obras, feitos, ações e instituições: as artes, as ciências, a filosofia, os ofícios, a religião e o Estado" (CHAUÍ, 1999, p. 356).

No primeiro sentido a Cultura considera o homem como um ser natural, todavia diferente dos animais e das plantas, pois possui uma natureza que precisa ser domada, educada para não se tornar agressiva. Cultura é o aprimoramento da natureza humana.

No segundo sentido, cultura passou a significar a expressão das obras humanas numa civilização assim como a relação que os humanos socialmente organizados estabelecem com o tempo, com o espaço e com outros humanos.

Se no primeiro sentido, Cultura e Natureza se harmonizam, no segundo sentido elas são opostas. O motivo da oposição foi à compreensão, segundo Chauí (1999), de que a natureza opera mecanicamente enquanto que o homem é dotado de liberdade e razão, agindo por escolha, de acordo com os valores afins.

Carvalho e Ronchi (2005, p. 7) mencionam que, do século XVIII até o século XX os "estudiosos procuraram dissociar as capacidades humanas aprendidas das capacidades herdadas geneticamente", mas foi Kroeber, segundo os autores, no início do século XX, "quem separou definitivamente os aspectos culturais dos naturais". Essa evolução de conceitos passou a dar a cultura um sentido histórico.

Ainda para os autores supracitados, cultura é um conceito originário da Antropologia. $\mathrm{E}$ esta vê a cultura por outro ângulo. Abandona a relação com a história e com o tempo e considera em que momento e de que maneira o ser humano faz o mundo cultural surgir.

Os estudos da antropologia sobre cultura têm servido de base para outras áreas acadêmicas, inclusive as Ciências Sociais Aplicadas. Entretanto, não tem sido fácil para os teóricos afinarem-se sobre os conceitos de cultura associado à organização (CARVALHO E RONCHI, 2005).

Desta forma, surgem duas correntes teóricas dispostas a estudar e conceituar a cultura organização. Uma delas trabalha o conceito de cultura organizacional como um fenômeno 
antropológico e a outra estuda a cultura organizacional dentro de uma perspectiva funcional, ou seja, a cultura organizacional é formada e administrada de acordo com as percepções dos fundadores e primeiros líderes (SCHEIN, 2009).

Dentro de uma visão antropológica Motta (2006, p. 40 e 41) afirma que, a cultura organizacional é formada "por um complexo coletivo de representações mentais que ligam o material-imaterial, a infraestrutura e as superestruturas". Dentro desta perspectiva, a cultura organizacional é formada a partir de uma relação de interdependência entre a "cultura de empresa, em termos mais gerencial, e as estruturas sociais, a história, a formação de seu povo, o inconsciente impregnado no coletivo humano, as leis, a moral, enfim, todos os fatores formadores dos traços de seu povo".

Contribuído com está visão, Morgan (1996, p. 125), identifica como sendo a maneira mais fácil de identificar a natureza da cultura em uma organização, seria observar o dia-a-dia do grupo como um antropologista. Assim, este autor afirma que "as características de uma cultura que estão sendo observada gradualmente se tornarão evidentes à medida que se conheçam os padrões de integração entre os indivíduos, a linguagem que é utilizada, imagens e temas discutidos e rituais da rotina diária." Desta forma, ao se explorar os elementos racionais da cultura formada nas organizações, pode-se, obter explicações históricas para como decisões e ações são direcionadas no dia-dia da organização.

Com uma percepção diferente das trabalhadas pelos autores antropologistas, uma corrente de autores entre os quais se destacam Schein (1992, 2009), Cameron e Quinn (2006), Pettigrew (2007), Fleury (2007), Paz e Mendes (2008) que vem trabalhando o conceito de cultura organizacional dentro de uma perspectiva funcionalista, o que Zaccarelli (1986, p. 58), chama de um conceito de cultura organizacional escrito em "administês".

Essa abordagem foi observada por Lourenço e Ferreira $(2012$, p. 73$)$ nos resultados de sua pesquisa quando identificaram que os gestores "exercem uma forte influência sobre a cultura organizacional, uma vez que trazem consigo um conjunto de pressupostos, valores, perspectivas e artefatos, que são repassados para os outros atores organizacionais."

Desta forma, Cameron e Quinn (2006, 146p.), apresenta que dentro da abordagem funcional que os "pesquisadores e gerentes podem identificar diferenças entre culturas organizacionais, podem mudar culturas e podem, empiricamente, medir culturas." A cultura segundo essa abordagem "é um potencial preditor dos resultados organizacionais (como a eficácia)."

Assim, Schein (1992, p. 12), conceitua cultura organizacional como sendo "um padrão de suposições básicas compartilhadas, que foi aprendido por um grupo à medida que solucionava seus problemas de adaptação externa e de integração interna." Essa padronização tem funcionado de tal forma que foi validado pelo grupo e compartilhado com os novos integrantes da organização como sendo a forma correta de perceber, pensar e sentir a organização.

Partindo da concepção de Schein (1992) sobre cultura organizacional e incorporando elementos da política, Fleury (2007, p.22) concebe a cultura organizacional como sendo "um conjunto de valores e pressupostos básicos expressos em elementos simbólicos, que em sua capacidade de ordenar, atribuir significações, construir a identidade organizacional", agindo tanto como instrumento de comunicação e consenso quanto deixando oculto e até instrumentalizado as relações de dominação na organização. 
Pettigrew (2007, p. 147), apresenta em um nível mais profundo a cultura, como "um conjunto mais complexo de valores, crenças e pressupostos que definem os modos pelos quais uma empresa conduz seus negócios." Esse autor defende que, essas crenças e pressupostos são manifestos nas estruturas, sistemas e símbolos, mitos e padrões de recompensas presentes no ambiente organizacional.

Por sua vez, Richter (2002. p.33 - 36) define cultura organizacional como sendo, "uma forma de interpretação da realidade organizacional que se transforma numa 'fôrma' ou molde para lidar com as questões organizacionais". Todavia, este autor destaca que, a "essência da construção da cultura organizacional parece estar localizada no próprio domínio psíquico dos integrantes da organização". O domínio psíquico seria o aspecto central da postura ou interpretação que os membros da organização têm com relação ao conhecimento.

Essa abordagem funcional de cultura organizacional é sustentada por Paz, Mendes e Gabriel (2001, p. 148-149) quando afirmam que "o caráter, apesar de estruturar-se no nível individual, é compartilhado nas organizações por meio de padrões de comportamento que tendem a se repetir para a maioria dos membros da organização", observando-se que os indivíduos dentro das organizações estão submetidos às mesmas condições de trabalho que delineiam a estrutura organizacional.

Entretanto, mesmo a cultura organizacional sendo formada a partir dos pressupostos do seu líder maior (SCHEIN, 2009), Paz e Teixeira (2009, p. 9), apresenta a importância de se estudar as organizações como coletividades "e os valores organizacionais investigados como compartilhamento, mesmo admitindo que o ambiente organizacional não é monolítico." Assim, essa perspectiva necessita de uma atenção, ainda que os aspectos constituintes da cultura organizacional sejam estudados individualmente.

Finalmente, é necessário destacar a importância de se considerar os aspectos mais objetivos das organizações (estrutura, nível de tecnologia, estratégia, estilo de liderança e poder) e seus indivíduos (caráter) para se entender e se gerenciar a sua cultura (CAMERON E QUINN, 2006) e (PAZ, MENDES E GABRIEL 2001).

\section{CULTURA ORGANIZACIONAL A PARTIR DO MODELO DE PAZ E MENDES}

Ao se considerar a ambiguidade e complexidade que envolve o tema "cultura organizacional", todo tipo de modelagem configura-se em uma vertente simplista, pois, não conseguirá corresponder à realidade em todos os seus matizes. Santos $(2000, p .56)$ cita que "uma vantagem especial da tipologia de atributos culturais é sua habilidade de empiricamente examinar a extensão na qual os elementos de uma cultura são congruentes. [...] Através da tipologia cultural, também se torna possível determinar se as organizações são dominadas por um certo tipo de atributo ou por vários".

Assim, o quadro 01 apresenta alguns dos autores que se "lançaram" na tentativa de propor modelos e tipologias para a análise da cultura organizacional. 
Quadro 01: Modelos de avaliação de cultura organizacional Fonte: Adaptado de Rocha (2010)

\begin{tabular}{|c|c|c|c|}
\hline Autor & Ano & Conceito & Características \\
\hline Handy & 1978 & $\begin{array}{l}\text { A cultura exprime melhor a } \\
\text { sensação de um modo de vida } \\
\text { ou conjunto difuso de } \\
\text { normas. }\end{array}$ & $\begin{array}{l}\text { Cultura do poder; } \\
\text { Cultura de papéis; } \\
\text { Cultura da tarefa; } \\
\text { Cultura da pessoa. }\end{array}$ \\
\hline Deal e Kennedy & 1982 & $\begin{array}{l}\text { O principal fator de influência } \\
\text { em uma cultura } \\
\text { organizacional é o ambiente } \\
\text { onde a organização opera, } \\
\text { sendo esta adaptação } \\
\text { importante para seu sucesso. }\end{array}$ & $\begin{array}{l}\text { Cultura Macho (Tough Guy/Macho } \\
\text { Culture); } \\
\text { Cultura Trabalho Duro/ Diverte Muito } \\
\text { (Work Hard/ Play Hard Culture); } \\
\text { Cultura Aposte Sua Empresa (Bet-Your- } \\
\text { Company Culture); } \\
\text { Cultura Processo (Process Culture). }\end{array}$ \\
\hline Sethia e Von Glinow & 1985 & $\begin{array}{l}\text { Consideram o sistema de } \\
\text { recompensas como uma } \\
\text { concreta e poderosa alavanca } \\
\text { para administração da cultura } \\
\text { na vida diária da organização, } \\
\text { dada uma relação de } \\
\text { interdependência entre } \\
\text { ambas. }\end{array}$ & $\begin{array}{l}\text { Cultura Apática; } \\
\text { Cultura Cuidadosa; } \\
\text { Cultura Exigente; } \\
\text { Cultura Integrativa. }\end{array}$ \\
\hline Donnelly & 1984 & $\begin{array}{l}\text { Relaciona-se a cultura com o } \\
\text { planejamento, dizendo ser } \\
\text { necessário que a definição de } \\
\text { cultura seja modificada para } \\
\text { incluir a influência que os } \\
\text { líderes organizacionais } \\
\text { exercem sobre ela, em virtude } \\
\text { da estrutura inerente ao } \\
\text { funcionamento de toda } \\
\text { organização. }\end{array}$ & $\begin{array}{l}\text { Cultura Excelente; } \\
\text { Cultura Confusa (Fuzzy); } \\
\text { Cultura Desagradável (Awful). }\end{array}$ \\
\hline Hofstede & $\begin{array}{l}1982, \\
1990 \\
1997\end{array}$ & $\begin{array}{l}\text { A cultura, sendo uma } \\
\text { programação coletiva da } \\
\text { mente, é determinada pelas } \\
\text { interações estabelecidas em } \\
\text { sociedade. }\end{array}$ & $\begin{array}{l}\text { Individualismo - Coletivismo; } \\
\text { Distância do poder; } \\
\text { Rejeição à incerteza; } \\
\text { Masculinidade - Feminilidade; } \\
\text { Orientação a Longo Prazo. }\end{array}$ \\
\hline Cameron e Quinn & 2006 & $\begin{array}{l}\text { O modelo assume que as } \\
\text { organizações } \\
\text { podem ser caracterizadas de } \\
\text { acordo com os traços culturais } \\
\text { ou dimensões comuns, sendo } \\
\text { a identificação de aspectos } \\
\text { que refletem valores e } \\
\text { suposições centrais das } \\
\text { organizações, a chave para } \\
\text { avaliar a cultura } \\
\text { organizacional. }\end{array}$ & $\begin{array}{l}\text { Cultura Clã ou Grupal; } \\
\text { Cultura Hierárquica; } \\
\text { Cultura de Adhocracia ou Inovativa; } \\
\text { Cultura de Mercado ou Racional }\end{array}$ \\
\hline
\end{tabular}

Dentro de uma perspectiva funcionalista da cultura organizacional, Paz e Mendes (2008), desenvolvem um o modelo denominado de Estilos de Funcionamento Organizacional que tem por objetivo, proporcionar uma compreensão da cultura organizacional. Esse modelo possibilita a compreensão da cultura coorporativa a partir dos padrões comportamentais compartilhados pela 
maioria dos seus membros, que se estruturam tomando por parâmetro as relações simbólicas que as pessoas estabelecem com suas organizações.

Assim, os estilos de cultura organizacional são avaliados através de um instrumento, capaz de definir os padrões de comportamentos compartilhados pela maioria dos integrantes de uma organização, que adotam como parâmetros as relações simbólicas estabelecidas entre as pessoas e suas organizações.

No entendimento de Paz, Mendes e Gabriel (2001), um indivíduo adulto que possua todos os traços de caráter em equilíbrio ou até mesmo a predominância de um dos estilos culturais, quando submetido a um contexto de uma organização diferente da que ele vivencia, as relações simbólicas entre eles revelam padrões comportamentais de regressão a fase mais primária do desenvolvimento humano.

Com base na estrutura teórica utilizada por Gabriel (1999), que apresenta os estilos narcisista, obsessivo, coletivista, individualista heroico e cívico; mas com uma denominação diferente, Paz e Mendes (2008) elaboraram 05 (cinco) os seus estilos com o objetivo de pesquisar o funcionamento organizacional no que diz respeito às relações entre organização e seus integrantes dentro de uma perspectiva associada ao desenvolvimento individual.

Estes estilos de funcionamento das organizações sugeridos por Paz e Mendes (2008) são identificados como: individualista, burocrático, afiliativo, empreendedor e cívico. As principais características destes estilos estão elencadas conforme quadro 02.

Quadro 02: Estilos de funcionamento das organizações

Fonte: Adaptado de Paz e Mendes (2008)

Estilo de

Funcionamento

\begin{tabular}{|l|l|}
\hline \multirow{5}{*}{ Individualista } & $\begin{array}{l}\text { Apresenta modos de sentir, pensar e agir que refletem uma fusão entre o indivíduo e } \\
\text { a organização. Desta forma, fica evidenciado que a predominância é o } \\
\text { comportamento voltado para a preocupação com o próprio bem-estar. Este estilo } \\
\text { não proporciona que a organização cresça, em função de comportamentos primários } \\
\text { existentes que podem gerar conflitos, competição e a falta de compromisso com a } \\
\text { organização entre os indivíduos. }\end{array}$ \\
\hline Burocrático & $\begin{array}{l}\text { Caracteriza-se por apresentar formas de pensar, sentir e agir baseados no controle de } \\
\text { normas e regras. Os integrantes dessa cultura apresentam comportamentos } \\
\text { marcados pelo envolvimento parcial perante a organização buscando segurança, } \\
\text { onde a lealdade ao setor no qual estão lotados sobressai à organização. } \\
\text { Culturalmente, o processo de mudança organizacional encontra resistência e seus } \\
\text { integrantes negam-se a criatividade. Nesse estilo, a estrutura organizacional } \\
\text { proporciona o conforto buscado pelos seus integrantes, no sentido de preservar a } \\
\text { rotina, o tempo, o controle e as regras. Por fim, este estilo pode dificultar a evolução } \\
\text { organizacional. }\end{array}$ \\
\hline Afiliativo & $\begin{array}{l}\text { Revela um jeito de sentir, pensar e agir que representa a organização como um grupo } \\
\text { de padrão ideal, refletindo orgulho, confiança e autoestima organizacional. Nessa } \\
\text { cultura, os integrantes procuram acima de tudo preservar a imagem da organização, } \\
\text { deixando transparecer que ela é perfeita e quaisquer tipos de imperfeições são } \\
\text { atribuídos a fatores externos. Assim, seus membros apresentam atitudes de lealdade, } \\
\text { corporação e dependência. Nesse estilo os integrantes evitam os confrontos internos, } \\
\text { os quais deixam de existir evitando uma quebra no coletivismo, uma vez que os } \\
\text { interesses e responsabilidades organizacionais são colocados acima dos pessoais. } \\
\text { Para manter tal situação, as pessoas tendem a obedecer às determinações do chefe }\end{array}$ \\
\hline
\end{tabular}




\begin{tabular}{|l|l|}
\hline Empreendedor & $\begin{array}{l}\text { sem procurar questioná-lo, respeitando a autoridade e mantendo perfeita sua } \\
\text { imagem, a qual encontra respaldo no grupo. }\end{array}$ \\
\hline $\begin{array}{l}\text { Revela um jeito de sentir, pensar e agir que representa a organização como um grupo } \\
\text { de padrão ideal, refletindo orgulho, confiança e autoestima organizacional. Nessa } \\
\text { cultura, os integrantes procuram acima de tudo preservar a imagem da organização, } \\
\text { deixando transparecer que ela é perfeita e quaisquer tipos de imperfeições são } \\
\text { atribuídos a fatores externos. Assim, seus membros apresentam atitudes de lealdade, } \\
\text { corporação e dependência. Nesse estilo os integrantes evitam os confrontos internos, } \\
\text { os quais deixam de existir evitando uma quebra no coletivismo, uma vez que os } \\
\text { interesses e responsabilidades organizacionais são colocados acima dos pessoais. } \\
\text { Para manter tal situação, as pessoas tendem a obedecer às determinações do chefe } \\
\text { sem procurar questioná-lo, respeitando a autoridade e mantendo perfeita sua } \\
\text { imagem, a qual encontra respaldo no grupo. }\end{array}$ \\
$\begin{array}{l}\text { É voltado para as relações de reciprocidade, pois se trata de uma cultura em que a } \\
\text { organização investe na admiração dos seus membros em função do que fazem. Nesse } \\
\text { estilo, as regras são sujeitas as críticas e as modificações, mas os sentimentos de } \\
\text { cidadania e ideais do bem comum são valorizados, favorecendo que seus membros } \\
\text { reconheçam a sua competência, valorizem o trabalho exercido, obedeça às regras, } \\
\text { critiquem seu desempenho e estejam sempre buscando o crescimento. }\end{array}$ \\
\hline
\end{tabular}

Após apresentado o modelo teórico dos estilos que regem o funcionamento das organizações Paz e Mendes (2008), elaboram uma proposta de instrumento de intervenção para identificar estes estilos nas organizações.

Para a construção do instrumento, Paz e Mendes (2008, p. 196) realizou uma pesquisa qualitativa com membros de diferentes organizações que totalizaram 20 indivíduos "para identificar se ocorriam comportamentos compartilhados e característicos de cada estilo". A análise de conteúdo dessas entrevistas permitiu a construção de categorias para cada estilo de cultura organizacional, todavia, os estilos empreendedores e cívicos se apresentaram de maneira muito semelhante.

Tanto as definições operacionais dos estilos propostas quanto às entrevistas deram subsídios para a elaboração dos itens da Escala. Para tanto os itens foram submetidos a oito juízes, que testaram a pertinência item-fator, em seguida os itens foram submetidos a compreensão semântica por 26 trabalhadores de organizações públicas e privadas, sendo realizadas pequenos ajustes na redação final dos itens (PAZ E MENDES 2008)

Neste contexto Paz e Mendes (2008, p. 170), "agrupou itens dos estilos empreendedor e cívico, passando e ser denominado de estilo do funcionamento empreendedor, em função da proximidade com o contexto organizacional atual."

Desta forma o modelo de intervenção desenvolvido por Paz e Mendes (2008), em sua versão final apresenta 30 itens que são analisados em uma escala de cinco pontos, que vai possibilitar identificar a predominância dos estilos de funcionamento das organizações apresentados no quadro 03, esses itens foram validados após a aplicação do EEFO com 416 empregados de duas organizações privadas e duas públicas, obtendo-se os $\alpha$ de Cronbach com valores superiores a 0,7 conforme quadro 03.

Quadro 03: Estilos de funcionamento das organizações

Fonte: Adaptado de Paz e Mendes (2008) 


\begin{tabular}{|l|l|c|}
\hline & cidadania. & 0,80 \\
\hline Afiliativo & $\begin{array}{l}\text { União, coesão e identificação com o } \\
\text { grupo de trabalho e com a organização. }\end{array}$ & 0,83 \\
\hline Individualista & $\begin{array}{l}\text { Necessidade de receber atenção e } \\
\text { atender, de forma enfática, os interesses } \\
\text { pessoais. }\end{array}$ & 0,79 \\
\hline Burocrático & $\begin{array}{l}\text { Controle, funcionamento de regras, } \\
\text { normas, ordem e hierarquia. }\end{array}$ & 0,82 \\
\hline
\end{tabular}

De forma conclusiva, o modelo teórico apresentado nesta discussão permitiu o presente estudo atingir o seu objetivo proposto, identificando as tipologias bem como algumas características da cultura organizacional presentes do Centro de Formação de Praças da Polícia Militar do RN.

\section{METODOLOGIA}

Por se propor a descrever os elementos que compõem a cultura organizacional no caso específico do CFAPM, bem como identificar a influencia das características sócio demográficas dos indivíduos estudados na definição dessa cultura, o presente estudo quanto aos objetivos é considerado descritivo. Segundo Gil (2010, p. 27), as "pesquisas descritivas têm como finalidade realizar a descrição das características de determinada população e podem ser elaboradas também com a finalidade de identificar possíveis relações entre variáveis." Nesse sentido, Santos, Molina e Dias (2007, p. 126) concordam quando afirmam que a pesquisa descritiva "é utilizada quando o pesquisador tem o intuito de descrever e caracterizar algum fenômeno, por exemplo, as características de um grupo específico." Quanto aos procedimentos esta pesquisa classifica-se como sendo um estudo de caso, que segundo Yin (2005) é uma investigação empírica abrangente, com procedimentos preestabelecidos, que investiga um ou múltiplos fenômenos contemporâneos no contexto da vida real, especialmente quando os limites entre os fenômenos e seu contexto não estão claramente definidos. Por fim, quanto à natureza dos dados, o presente estudo é considerado predominantemente quantitativo.

Este trabalho estudou as características de cultura organizacional presente no Centro de Formação de Praças da Polícia Militar do Rio Grande do Norte - CFAPM. Para tal, foram definidos como população todos os policiais militares lotados no Centro de Formação e Aperfeiçoamento da Polícia Militar do Estado do Rio Grande do Norte, totalizando 60 (sessenta) policiais, sendo 08 (oito) oficiais e 52 (cinquenta e duas) praças. 0 estudo não utilizou amostra, foi do tipo censitário abrangendo a totalidade da população.

Os dados foram coletados por meio da aplicação de questionário, definida por Collis e Hussey (2005, p. 165) como sendo "uma lista de perguntas cuidadosamente estruturadas, escolhidas após a realização de vários testes, tendo em vista a obtenção de respostas confiáveis de uma amostra escolhida." Para efeito desta pesquisa, foi utilizado um questionário com um total de 35 (trinta e cinco) perguntas fechadas, divididas em 05 (cinco) questões gerais, que permitiram identificar as características gerais dos policiais militares pesquisados, e 30 (trinta) 
questões elaboradas com base nos modelos teóricos propostos por Paz e Mendes (2008) - EEFO, com o objetivo de identificar as tipologias culturais existentes na organização estudada. 0 instrumento foi validado com índices de previsão Alfa de Cronbach variando de 0,79 a 0,83 para os quatro fatores presentes no modelo conforme quadro 03.

A aplicação do questionário foi realizada entre os dias 15 e 25 de agosto de 2011, no qual foram aplicados 59 questionários tendo retornado em condições de tabular todos os 59 . Apenas um policial não foi pesquisado, pois, este é autor da pesquisa.

Por fim, a análise dos resultados utilizando a EEFO foi realizada por meio da estatística descritiva com o cálculo da média em relação à escala de 5 (cinco) pontos com variação de 0 (zero) a 4 (quatro), no qual o ponto médio foi considerado 2 (dois), sendo as medidas próximas a esse ponto consideradas como uma presença moderada de determinado estilo de funcionamento organizacional, enquanto que acima de 2,5 (dois vírgula cinco), o estilo foi considerado predominante e abaixo de 1,5 (um vírgula cinco), o padrão foi considerado pouco característico. Além do cálculo da média, foi utilizado para se verificar as relações entre o perfil sócio demográfico e os estilos de funcionamento organizacional a estatística não paramétrica sendo adotado: o teste de Qui-quadrado $\left(\chi^{2}\right)$, onde utilizou-se a tabela de contingência $2 \times 2$, para a análise da associação entre as variáveis interligadas (questões específicas) e as variáveis independentes (questões gerais); o Teste Exato de Fisher e a Análise de Correspondência. Os dados foram tabulados com a ajuda do programa SPSS 17.0.

\section{ESTILOS DE CULTURA ORGANIZACIONAL PRESENTES NO CFAPM NATAL/RN}

Ao se observar os estilos de funcionamento organizacional existentes no CFAPM, percebese a presença de apenas 03 (três) tipologias de cultura organizacional que foram os estilos: afiliativo em $55,9 \%$, empreendedor em $28,9 \%$ e o burocrático em $15,2 \%$ dos policiais, não sendo identificada a ocorrência do estilo individualista.

Deste modo, percebe-se que o estilo de cultura predominante no Centro de Formação e Aperfeiçoamento da Polícia Militar do Rio Grande do Norte é o estilo Afiliativo, o qual segundo Paz e Mendes (2008), apresenta um jeito de sentir, pensar e agir que retrata a organização como um grupo perfeito, refletindo orgulho, confiança e autoestima organizacional, refletindo a coesão e a união dos policiais militares desse Centro de Formação, o que demonstra características de um padrão unicamente coletivista, definindo assim, com 55,9\%, a predominância dessa tipologia.

As organizações com esse tipo de estilo agem de forma a oferecer segurança e vantagens que favorecem a percepção de grandiosidade da organização, favorecendo que seus membros permaneçam numa situação de conformismo, de forma a aceitar as normas e regras impostas pelo grupo sem maiores questionamentos. Desta forma, pode-se afirmar que, a organização com este estilo de cultura, acaba tolhendo o desenvolvimento dos seus funcionários fazendo com que só aconteça uma busca pelo desenvolvimento quando os interesses partem da organização.

O estilo cultural empreendedor apresentou-se nos resultados da pesquisa como a segunda tipologia mais observada no CFAPM, com 28,9\% dos estilos. Para Paz e Mendes (2008), a instituição que apresenta este estilo prima pela inovação e pela competência e valoriza relações de trocas bem estabelecidas, além de apresentar funcionamento que favorece a interação profissional e a promoção de um maior bem estar entre os integrantes do grupo. É formada por pessoas que almejam conquistar um lugar distinto na organização, mas respeitando a conexão com os outros e a aceitação de que todos possam ter realizações, o que é possível. 
A tipologia cultural identificada no CFAPM que apresentou o menor índice percentual dentre os 03 (três) estilos culturais identificados, foi o estilo burocrático, que apresenta características culturais com um forte sistema de regras, no qual Paz e Mendes (2008) destacam um rígido controle disciplinar no trabalho, resgatado de organizações com forte estrutura hierárquica e pouca flexibilidade, o que valoriza o planejamento. Trata-se de uma cultura que investe pouco na atenção aos problemas pessoais dos seus membros, de forma que os laços de amizade entre as pessoas, à organização e seus membros não são fortes. Desta maneira, os pesquisadores identificaram, no presente estudo, 09 (nove) policiais militares com essas características culturais.

A presença do estilo burocrático atingindo o terceiro índice percentual na pesquisa devese ao fato de que as atividades desenvolvidas naquela Unidade Escola visam atingir a formação profissional coletiva no nível base da Corporação, ou seja, é uma organização que mesmo visando acompanhar as necessidades da sociedade e primando para que seus ensinamentos permeiem a legalidade, ainda possui fortes traços doutrinários, colaborando assim, para a não predominância desse estilo cultural.

De acordo com Schein (2009), apesar da cultura ser criada por experiências compartilhadas, é o líder ou o gestor principal que inicia esse processo ao impor as suas crenças. Neste sentido, esse padrão cultural vai depender do impacto causado pelas crenças, valores e suposições dos seus fundadores e como essas características se relacionam com as experiências de aprendizado das pessoas e as novas crenças, valores e suposições introduzidas por novos membros e/ou líderes.

\section{RELAÇÕES ENTRE AS CARACTERÍSTICAS SÓCIO DEMOGRÁFICAS E AS TIPOLOGIAS DE CULTURA ORGANIZACIONAL DO CFAPM}

As últimas análises realizadas na pesquisa buscam identificar, por meio de técnicas estatísticas do Teste de Qui-quadrado para associação linear e do Teste Exato de Fisher, as relações existentes entre os estilos de cultura organizacionais propostos por Paz e Mendes (2008) e as variáveis sócio demográficas dos policiais lotados no CFAPM. Neste sentido, Agresti (2007), afirma que quando o pesquisador tem interesse em observar se as variáveis categorizadas são estatisticamente dependentes utiliza-se este teste.

Já para visualizar as associações entre as variáveis categorizadas foi aplicada aos dados a técnica de Análise de Correspondência, que segundo Hair et al (2009), consiste em uma análise exploratória de dados e é feita a partir de uma representação gráfica desta associação. Este método permite estudar as relações existentes entre os estilos culturais dos policiais pesquisados e suas características tais como: a faixa etária, o nível de escolaridade e o tempo de serviço.

Assim, para verificar a relação existente entre os estilos culturais e a faixa etária dos policiais, a presente análise foi composta pela relação entre os estilos afiliativo, empreendedor e burocrático com as respectivas faixas etárias dos policiais estudados, sendo utilizado o Teste de Qui-quadrado para associação linear.

Foi calculado também o valor-p nas verificações das relações existentes entre os estilos culturais e as características gerais dos pesquisados, o qual é uma estatística utilizada para sintetizar o resultado de um teste de hipóteses. Formalmente, esse valor é definido como a 
probabilidade de se obter uma estatística de teste igual ou mais extrema quanto àquela observada em uma amostra, assumindo verdadeira a hipótese nula.

Para identificar as faixas etárias dos policiais, os pesquisadores ofereceram 08 (oito) faixas, para que os pesquisados se identificassem consoante as suas idades, entretanto para analisar os resultados optaram por agrupá-las em apenas 03 (três), quantidade necessária para se testar as relações entre as variáveis.

Tabela 01: Faixa etária dos policiais pesquisados versus cultura organizacional

\begin{tabular}{c|c|c|c|c|c}
\hline \multirow{2}{*}{ Faixa Etária } & \multicolumn{3}{|c|}{ Estilo de Funcionamento } & \multirow{2}{*}{ Total } & \multirow{2}{*}{ Valor-p } \\
\cline { 2 - 4 } & Afiliativo & Empreendedor & Burocrático & & \\
\hline Até 30 anos & $09(52,9)$ & $05(29,4)$ & $03(17,7)$ & $17(100,0)$ & \\
\hline De 31 a 40 anos & $14(51,9)$ & $08(29,6)$ & $05(18,5)$ & $27(100,0)$ & \multirow{2}{*}{0,0370} \\
\hline Mais de 40 anos & $10(66,7)$ & $04(26,7)$ & $01(6,7)$ & $15(100,0)$ & \\
\hline Total & 33 & 17 & 09 & 59 & \\
\hline
\end{tabular}

Fonte: Dados da pesquisa 2011.

(\%) Valores em porcentagem.

Em relação à primeira variável abordada, a faixa etária dos policiais, 27 (vinte e sete) estão inseridos na faixa etária que vai dos 31 aos 40 anos de idade, representando $45,8 \%$ dos pesquisados, conforme especifica a Tabela 01, dos quais mais da metade colabora com a predominância do estilo afiliativo, contribuindo dessa forma para que esta faixa etária seja também predominante em todos os outros estilos culturais.

Ao nível de significância de $5 \%$ (cinco por cento), identifica-se que existe associação significativa entre a faixa etária de policiais de 31 a 40 anos e os estilos de funcionamento afiliativo. Isso demonstra que por se tratar de um grupo com mais de 10 anos na polícia militar estes já incorporaram a hierarquia e disciplinas presentes nos valores institucionais, isto é posto quando Paz e Mendes (2008) afirmam que no estilo cultural afiliativo as pessoas tendem a obedecer às determinações do chefe sem procurar questioná-lo, respeitando a autoridade e mantendo perfeita sua imagem, a qual encontra respaldo no grupo.

A segunda técnica utilizada foi a Análise de Correspondência com o objetivo de verificar quais os estilos de funcionamento organizacional estariam mais associados a cada uma das faixas etárias. Verificou-se então, que o estilo afiliativo está mais associado aos policiais com idade superior a 40 anos, que o estilo empreendedor está associado a faixa etária que vai até os 30 anos e por fim, o estilo burocrático que engloba os militares com idade entre 31 e 40 anos, conforme observado no Gráfico 01. O que reforça o que foi identificado no Teste de Quiquadrado (Tabela 01) o qual apresenta uma tendência dos policiais com idade superior a 30 anos a se posicionarem entre os padrões culturais burocrático e afiliativo. Padrão esse diferente dos policiais com idade inferior a 30 anos que se posicionam próximo da cultura empreendedora que segundo Paz e Mendes $(2008,173)$ esse tipo de cultura é "constituída por pessoas que buscam um lugar especial na sociedade, status e reputação, que tem necessidade de colocar-se no mundo de forma individualizada, mas respeitando a conexão social", tal análise justifica-se pela pouca idade dos policiais o que reflete a busca de um posicionamento melhor na instituição ou busca por novas oportunidade no mercado de trabalho. 


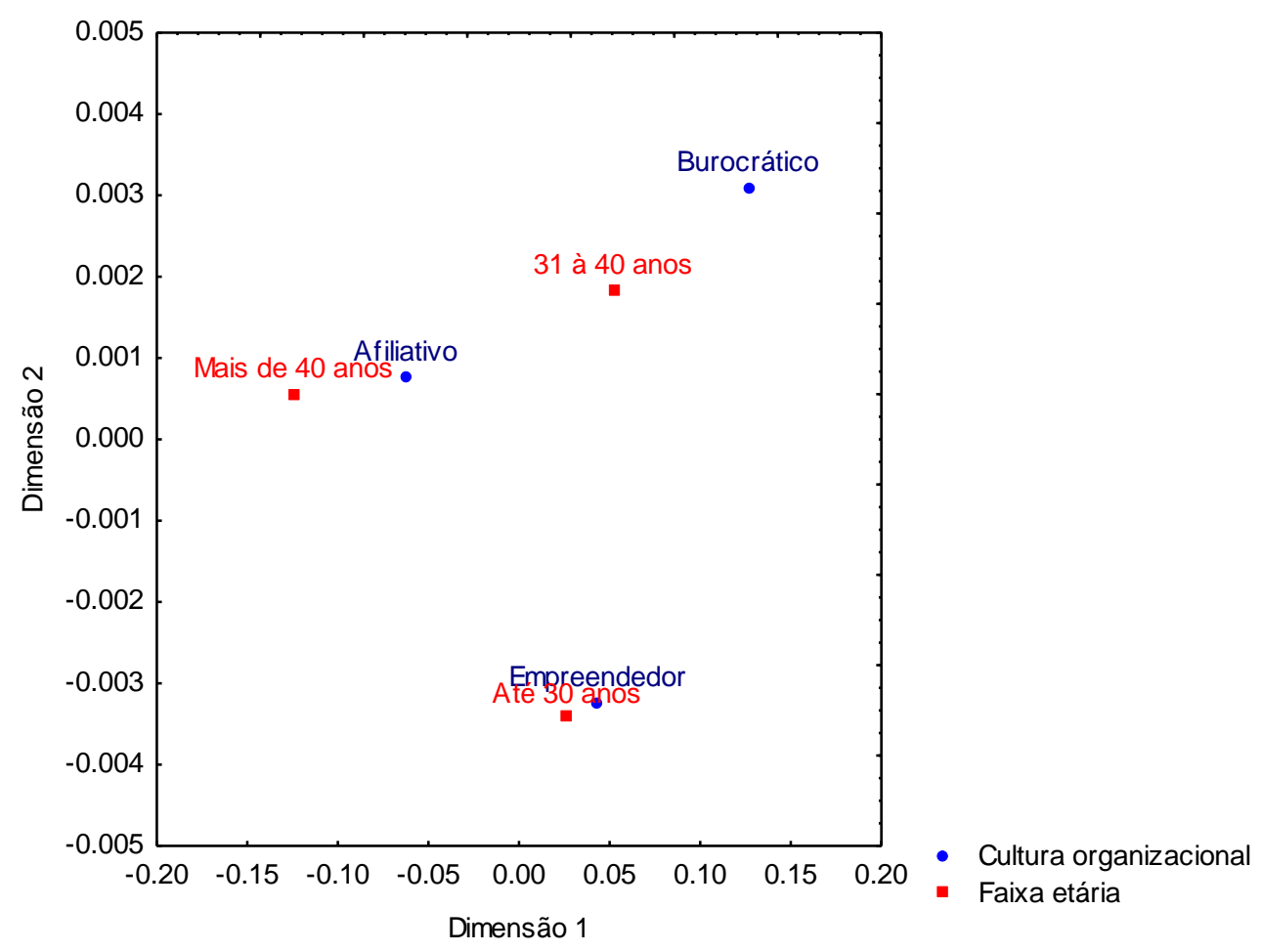

Gráfico 01: Análise de Correspondência entre a faixa etária e cultura organizacional. Fonte: Dados da pesquisa 2011.

No que se refere ao nível de escolaridade, foi utilizado o Teste de Qui-quadrado para associação linear com o objetivo de verificar a relação existente entre os estilos culturais e o nível de escolaridade dos policiais. Para isso, a Tabela 02 foi composta pela correlação dos estilos afiliativo, empreendedor e burocrático com os seguintes graus de instrução: ensino fundamental, ensino médio, ensino superior completo ou incompleto e pós-graduação.

Ao nível de significância de $10 \%$ (dez por cento), identifica-se que existe associação significativa entre os policiais de nível superior e médio com o estilo de funcionamento afiliativo. Apesar de se apresentar um considerável número de policiais com nível superior esses policiais vivenciam as rotinas, crenças, valores e ritos de uma instituição militar, o que justifica um posicionamento cultural de conformismo com normas e regras sem questionamento, na tentativa de ser aceito pelo grupo (PAZ E MENDES, 2008).

Tabela 02: Nível de escolaridade dos policiais pesquisados versus cultura organizacional

\begin{tabular}{c|c|c|c|c|c}
\hline \multirow{2}{*}{ Escolaridade } & \multicolumn{3}{|c|}{ Estilo de Funcionamento } & \multirow{2}{*}{ Total } & \multirow{2}{*}{ Valor-p } \\
\cline { 2 - 4 } & Afiliativo & Empreendedor & Burocrático & & \\
\hline Fundamental & $01(25,0)$ & $02(50,0)$ & $01(25,0)$ & $04(100,0)$ & \\
\hline Médio & $14(50,0)$ & $08(28,6)$ & $06(21,4)$ & $28(100,0)$ & \\
\hline Superior & $16(69,6)$ & $05(21,7)$ & $02(8,7)$ & $23(100,0)$ & \multirow{2}{*}{0,089} \\
\hline Pós-Graduação & $02(50,0)$ & $02(50,0)$ & $00(0,0)$ & $04(100,0)$ & \\
\hline Total & 33 & 17 & 09 & 59 & \\
\hline
\end{tabular}

Fonte: Dados da pesquisa 2011.

(\%) Valores em porcentagem. 
Ao se observar a técnica de Análise de Correspondência identificou-se que assim como o Teste de Qui-quadrado (tabela 02) obteve-se uma forte relação entre o estilo cultural afiliativo e os policiais com nível superior. Tal resultado confirma a análise feita em relação a tabela 02.

Por fim, identificou-se ainda um bom nível de escolaridade dos policiais, uma vez que $46 \%$ possuem escolaridade entre nível superior e pós-graduação e apenas 6,8\% apresentam o ensino fundamental.

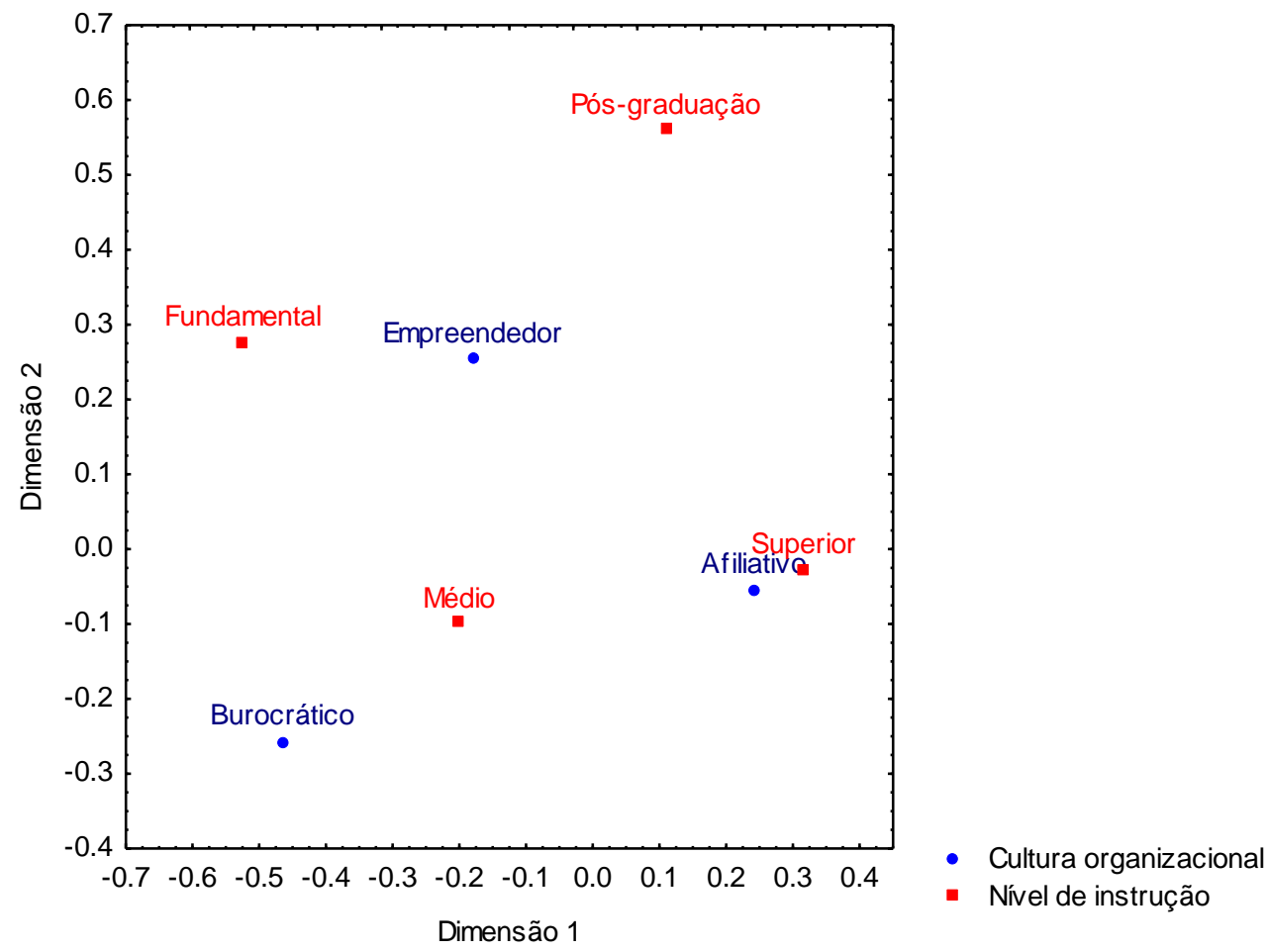

Gráfico 02: Análise de Correspondência entre os níveis de escolaridade e cultura organizacional. Fonte: Dados da pesquisa 2011.

Outra variável analisada foi o tempo de serviço na Corporação. Dentre os 59 pesquisados, observa-se que $71,3 \%$ desse efetivo não ultrapassam 15 anos de serviço. Observa-se ainda que deste percentual de policiais com tempo na corporação até 15 anos, existe uma maior concentração destes no estilo cultural afiliativo.

Tabela 03: Tempo de serviço dos policiais pesquisados versus cultura organizacional

\begin{tabular}{c|c|c|c|c|c}
\hline \multirow{2}{*}{ Faixa Etária } & \multicolumn{3}{|c|}{ Estilo de Funcionamento } & \multirow{2}{*}{ Total } & \multirow{2}{*}{ Valor-p } \\
\cline { 2 - 4 } & Afiliativo & Empreendedor & Burocrático & & \\
\hline Até 05 anos & $10(50,0)$ & $06(30,0)$ & $04(20,0)$ & $20(100,0)$ & \\
\hline De 06 a 10 anos & $06(66,7)$ & $02(22,1)$ & $01(11,1)$ & $09(100,0)$ & \\
\hline De 11 a 15 anos & $06(46,2)$ & $04(30,8)$ & $03(23,1)$ & $13(100,0)$ & \multirow{2}{*}{0,0269} \\
\hline De 16 a 20 anos & $02(40,0)$ & $03(60,0)$ & $00(0,0)$ & $05(100,0)$ & \\
\hline De 21 a 25 anos & $04(66,7)$ & $02(33,3)$ & $00(0,0)$ & $06(100,0)$ & \\
\hline 26 anos ou mais & $05(83,3)$ & $00(0,0)$ & $01(16,7)$ & $06(100,0)$ & \\
\cline { 1 - 4 } Total & 33 & 17 & 09 & 59 & \\
\hline
\end{tabular}

Fonte: Dados da pesquisa 2011.

(\%) Valores em porcentagem. 
Ao nível de significância de $5 \%$ (cinco por cento), identifica-se que existe associação significativa entre o tempo de serviço prestado na Corporação e os estilos de funcionamento, bem como, observa-se que o estilo cultural afiliativo predomina na maioria das faixas de tempo de serviço.

Mesmo havendo significância estatística, utilizou-se a técnica exploratória de estatística multivariada de Análise de Correspondência com o objetivo de verificar quais os estilos de funcionamento organizacional estariam mais associados a cada faixa de tempo de serviço prestado pelos policiais pesquisados.

Verifica-se então, que o estilo afiliativo está mais associado a duas faixas de tempo de serviço especificadas da seguinte forma: de 06 a 10 anos e de 26 anos ou mais. Assim como o estilo anteriormente citado, o estilo empreendedor obteve forte tendência a se associar também a duas faixas, sendo elas: de até 05 anos e de 21 a 25 anos, enquanto que o estilo burocrático está associado a faixa que compreende 11 a 15 anos de serviço. Além disso, percebe-se que os militares que tem entre 16 a 20 anos de serviço não estão claramente associados a nenhum estilo cultural, conforme observado no Gráfico 03. Tal explicação se deve pelo fato de que, nessa faixa ficarem classificados o menor número de policiais, apenas 05 (cinco) militares, ou seja, 8,4\% de todo o efetivo pesquisado.

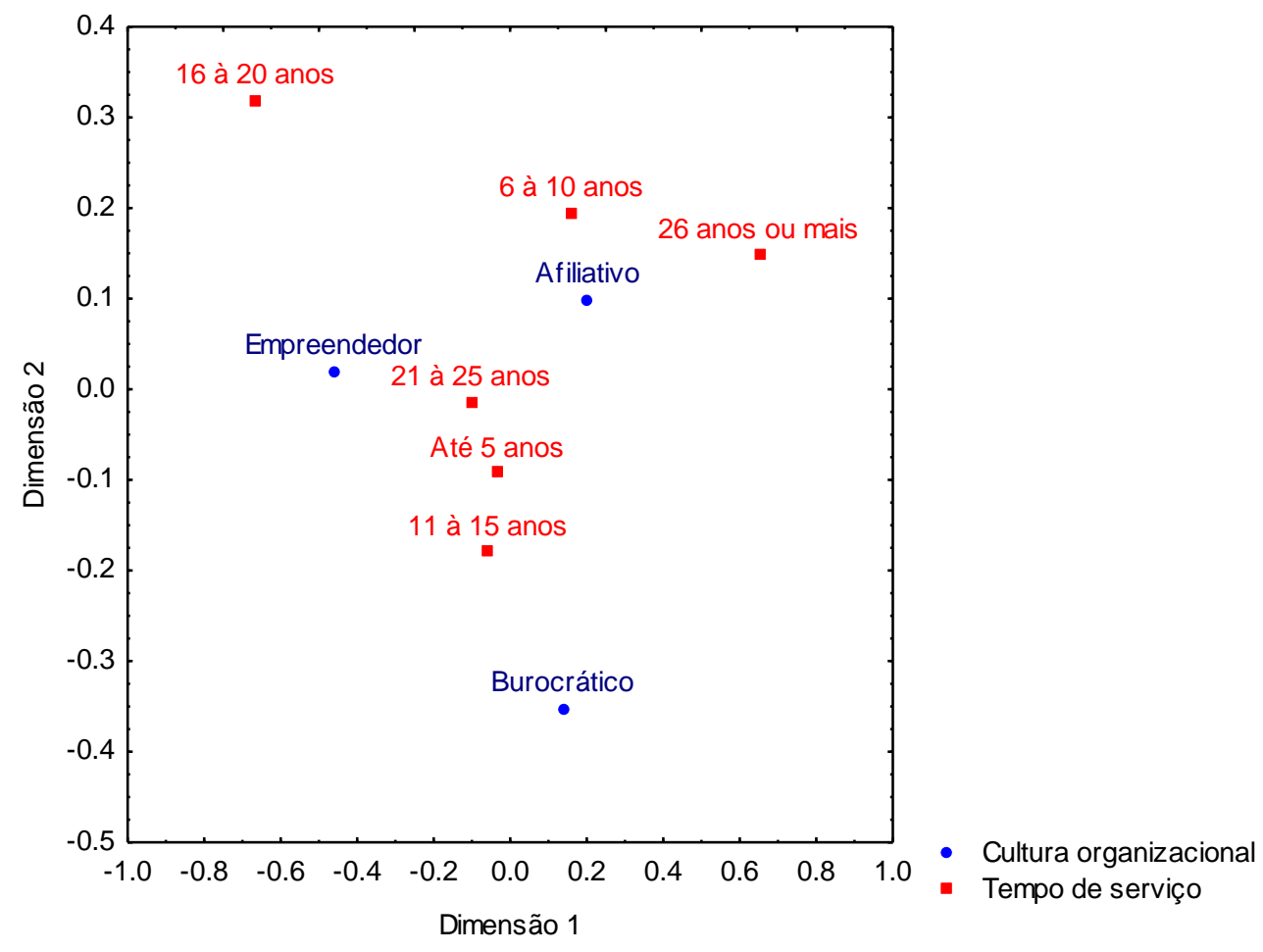

Gráfico 03: Análise de Correspondência entre tempo de serviço e cultura organizacional. Fonte: Dados da pesquisa 2011.

A pesquisa ainda mostra que existe uma tendência de que 03 faixas de tempo de serviço, sendo elas: de até 05 anos, de 11 a 15 anos e de 21 a 25 anos de serviço prestados, pertençam a um mesmo estilo cultural, perpassando pelos estilos afiliativo, empreendedor ou burocrático, isso equivale a $66,1 \%$ dos policiais pesquisados. 
Quanto as variáveis sexo e cargo exercido, o Teste de Qui-quadrado para associação linear não foi aplicado, uma vez que esse teste só se aplica quando há ordem nas variáveis categorizadas e quando nenhuma das suposições é violada, por isso utilizou-se o Teste Exato de Fisher. Quando se aplica o Teste de Qui-quadrado e o valor esperado é menor que $5 \%$, o grau de certeza na decisão não é exato, a alternativa é utilizar o Teste Exato de Fisher que é a versão exata do Teste de Qui-quadrado, ao contrário, quando a amostra é grande, o Teste Exato de Fisher não deve ser usado porque envolve o cálculo de fatoriais, o que pode conduzir a resultados com números excessivamente elevados.

Analisando a Tabela 04, observa-se que as variáveis categorizadas como características gerais dos policiais pesquisados (sexo e cargo exercido), não oferece ordem, restando somente duas opções para verificar se há ou não relação entre elas, não sendo possível a aplicação do Teste de Qui-quadrado para a associação linear, nem a Análise de Correspondência.

Tabela 04: Gênero e cargo dos policiais pesquisados versus cultura organizacional

\begin{tabular}{c|c|c|c|c|c|c}
\hline \multirow{2}{*}{ Variável } & \multicolumn{3}{c|}{ Estilo de Funcionamento } & \multirow{2}{*}{ Total } & \multirow{2}{*}{ Valor-p } \\
\cline { 3 - 5 } \multicolumn{2}{c|}{} & Afiliativo & Empreendedor & Burocrático & & \\
\hline \multirow{2}{*}{ Sexo } & Masculino & $33(57,9)$ & $15(26,3)$ & $09(17,3)$ & $57(100,0)$ & \multirow{2}{*}{0,0105} \\
\cline { 2 - 5 } & Feminino & $00(0,0)$ & $02(100,0)$ & $00(0,0)$ & $02(100,0)$ & \\
\hline \multirow{2}{*}{ Cargo } & Oficial & $06(85,7)$ & $01(14,3)$ & $00(0,0)$ & $07(100,0)$ & \multirow{2}{*}{0,0321} \\
\cline { 2 - 5 } & Praça & $27(51,9)$ & $16(30,8)$ & $09(15,8)$ & $52(100,0)$ & \\
\hline
\end{tabular}

Fonte: Dados da pesquisa 2011.

(\%) Valores em porcentagem.

Ao nível de significância de 5\% (cinco por cento), identifica-se que não existe associação significativa entre o gênero feminino e os estilos culturais ora pesquisados. Tal resultado se deu em virtude do efetivo de policiais femininos serem bastante reduzido no CFAPM. Entretanto, quando se trata do gênero masculino, observa a existência de uma elevada e significativa associação entre os estilos afiliativo e burocrático. Quanto à relação existente entre os cargos exercidos pelos militares e os estilos de funcionamento, pode-se observar uma forte relação entre os cargos de oficiais e praças com o estilo afiliativo. Ao analisar esta relação pode-se inquerir que os oficiais como lideres compartilham um padrão de suposições básicas que foram aprendidas palas praças à medida que resolviam seus problemas de adaptação ao meio externo e que tem funcionado de tal forma que foi padronizada entre esses policiais liderados (SCHEIN, 1992), refletindo uma mesma tipologia cultural para grupos hierarquicamente distintos.

Mesmo havendo significância estatística entre os estilos de funcionamento somente com o gênero masculino e os cargos exercidos pelos policiais pesquisados (masculino e feminino), não foi possível executar a Análise de Correspondência por terem sido abordadas apenas 02 categorias nas variáveis categorizadas, excluindo, dessa maneira, a possibilidade de ordem, o que impossibilitou a realização desta técnica exploratória.

Além disso, é importante afirmar que o Teste de Qui-quadrado para a associação linear permite identificar a correlação entre as características gerais e os estilos de funcionamento, diferentemente do Teste Exato de Fisher que assim como uma técnica estatística permite-se verificar as relações entre esses mesmos estilos e as características gerais quando estas não oferecem ordem, e sim apenas duas opções. 
Dessa maneira, observa-se que os resultados obtidos nesse estudo apresentaram a presença de uma cultura predominante e suas subculturas, a partir da percepção dos policiais participantes da presente pesquisa, de tal forma que essa cultura predominante e as subculturas encontradas dentro do CFAPM podem ser justificadas pelo fato de que mesmo as pessoas compartilhando muitas coisas em um mesmo ambiente organizacional, dificilmente predominará apenas um estilo cultural predominante a todos os componentes do grupo, em virtude dos diferentes modos de sentir, pensar e agir inerente a cada indivíduo.

\section{CONCLUSÕES}

Ao estudar elementos que compõem a cultura organizacional presente no Centro de Formação e Aperfeiçoamento da Polícia Militar do Estado do Rio Grande do Norte - Brasil (CFAPM) possibilitou se compreender as tipologias de cultura e as suas influencias no contexto de uma instituição militar de ensino.

De forma conclusiva observou-se o estilo afiliativo como cultura predominante na organização e o estilo empreendedor como uma subcultura, com suas peculiaridades.

No que se diz respeito às relações entre as características sócio demográficas e as tipologias culturais dos policiais lotados no CFAPM, percebe-se uma significativa influência das primeiras variáveis nos estilos culturais, confirmada com a indicação da predominância apresentada nos resultados. Assim, afirma-se de forma conclusiva que os resultados indicam uma significativa relação entre os estilos de funcionamento organizacional propostos por Paz e Mendes (2008) com as características gerais dos pesquisados.

Todavia, pode-se apontar uma limitação de ordem metodológica relacionada à pesquisa de cultura organizacional. Assim, as pesquisas que analisam a cultura organizacional pressupõem um maior aprofundamento, que foi impossibilitado por questões de ordem práticas, levando o pesquisador a desenvolver apenas um estudo quantitativo, todavia a pesquisa não é invalidada uma vez que segundo Silva, Medeiros e Enders (2011), as pesquisas quantitativas embora não se aproximem tanto quanto as pesquisas qualitativas da complexidade existente na cultura organizacional, esse estudos permitem realizar generalizações e comparações. Todavia, os autores afirmam ainda que os métodos quantitativos e qualitativos para o estudo da cultura organizacional não são excludentes, ficando assim, como recomendação para estudos futuros a combinação dos dois métodos com o uso da triangulação.

Por fim, fica ainda como recomendações de estudos futuros, identificar outros fatores organizacionais que possam influenciar a cultura organizacional, de forma a identificá-las no plano macro em relação a outros fatores pertencentes ao ambiente organizacional e sua interação com seus agentes. Para elaboração destes estudos se propõe o uso de modelos causais que permitam identificar múltiplas relações de interdependências.

\section{REFERÊNCIAS}

1. AGRESTI, Alan. An Introduction to Categorical Data Analysis. New Jersey, USA: John Wiley \& Sons, 2007.

2. CAMERON, K. S.; QUINN, R. E. Diagnosing and changing organizational culture. San Francisco: Jossey-Bass, 2006. 
3. CARVALHO, Carlos Eduardo; RONCHI, Carlos César. Cultura organizacional: teoria e pesquisa. Rio de Janeiro: Fundo de Cultura, 2005.

4. CHAUI, Marilena. Convite à Filosofia. São Paulo, ed. Ática, 1999.

5. COLLIS, Jill; HUSSEY, Roger. Pesquisa em administração: um guia prático para alunos de graduação e pós-graduação. 2. ed. Porto Alegre: Bookman, 2005.

6. FLEURY, Maria Tereza Leme. O desvendar de uma organização - uma discussão metodológica. In: FLEURY, M. T. Leme; FISCHER, R. Maria (Org.). Cultura e poder nas organizações. 2. ed. São Paulo: Atlas, 2007. p. $15-27$.

7. FREITAS, Maria Ester de. Cultura organizacional: formação, tipologias e impacto. São Paulo: Makron Books, 1991.

8. GABRIEL, Y. Organizational in depth. London: Sage, 1999.

9. GIL, Antônio Carlos. Como elaborar projetos de pesquisa. São Paulo: Atlas, 2010.

10. GUIMARÃES, T. A. A nova administração pública e a abordagem da competência. Revista de Administração Pública, Rio de Janeiro, v. 34, n. 3, p. 125-140, maio/jun. 2000.

11. HAIR, J. F.; ANDERSON, R. E.; TATHAM, R. L.; BLACK, W. C. Análise multivariada de dados. 6. ed. Porto Alegre: Bookman, 2005.

12. LOURENÇO, C. D. S; FERREIRA, P. A. Cultura Organizacional e o mito fundador: um estudo em uma empresa familiar. Gestão \& Regionalidade, v. 28, n. 84, p. 61-76, set-dez/2012.

13. MORGAN, Gareth. Imagens da organização. São Paulo: Atlas, 1996.

14. MOTTA, Fernando C. Pestes. Cultura organizacional e cultura brasileira. São Paulo: Atlas, 2006.

15. PAZ, Maria das G. Torres da; MENDES, Ana M. Bezerra; GABRIEL, lannis. Configurações de poder organizacional e estilos de caráter. Psicologia: organizações e trabalhos. Florianópolis, v. 1, n. 1, jan./jun. 2001.

16. PAZ, Maria das G. Torres da; MENDES, Ana M. Bezerra. Estilos de funcionamento organizacional. In: SIQUIERA, Mirlene Maria Matias (Org.). Medidas do comportamento organizacional: ferramenta de diagnóstico e de gestão. Porto Alegre: Artmed, 2008.

17. PAZ, Maria das G. Torres da; TEIXEIRA, Maria L. M. Introdução. RAM - Revista de Administração Mackenzie. São Paulo, v. 10, n.3, mai/jun. 2009.

18. PETTIGREW, Andrew M. A cultura das organizações é administrável?. In: FLEURY, M. T. Leme; FISCHER, R. Maria (Org.). Cultura e poder nas organizações. 2. ed. São Paulo: Atlas, 2007. p. $145-153$.

19. RICHTER, Fábio Andreas. Organizações do conhecimento: infra-estrutura, pessoas e tecnologias. ANGELONI, M.T. (Org.). São Paulo: Saraiva 2002.

20. ROCHA, Luiz C. S. Cultura e clima organizacionais: um estudo multicasos em indústrias de laticínios do Estado do Rio Grande do Norte. Dissertação (PPGA) - Universidade Federal do Rio Grande do Norte, Natal, 2010.

21. SANTOS, G. do R. C. M; MOLINA, N. L.; DIAS, V. F. Orientações e dicas práticas para trabalhos acadêmicos. Curitiba: Ibpex, 2007.

22. Organizational culture and leadership. 2.ed. San Francisco: Jossey-Bass, 1992. 
23. SCHEIN, Edgar H. Cultura Organizacional e liderança. São Paulo: Atlas, 2009.

24. SILVA, L. M. T; MEDEIROS, C. A. F.; ENDERS, W. T. Avaliação da cultura organizacional: um contraponto entre as abordagens quantitativas e qualitativas. INTERFACE. Natal, v.8, n. 2, jul./dez. 2011.

25. YIN, Robert K. Estudo de caso: planejamento e métodos. 3. ed. Porto Alegre: Bookman, 2005.

26. ZACCARELLI, Sérgio Batista. Estratégia e sucesso nas empresas. São Paulo: Saraiva, 2000. 